\title{
Prevalence of manifest hypermetropia in primary school children of Gaza city
}

\author{
Abuimara Amer, Tarshawi Mohammed \\ Islamic University - Gaza, Gaza, Palestine
}

Email address:

aabuimara@iugaza.edu.ps(A. Amer)

\section{To cite this article:}

Abuimara Amer, Tarshawi Mohammed. Prevalence of Manifest Hypermetropia in Primary School Children of Gaza City Science Journal of Public Health. Vol. 1, No. 3, 2013, pp. 131-134. doi: 10.11648/j.sjph.20130103.14

\begin{abstract}
Research question: what is the prevalence of manifest hypermetropia in primary school children (6-11 years ) of Gaza city? Objective: to study the prevalence of manifest hypermetropia in primary school children of Gaza city . Study design: cross sectional. Setting: schools of Gaza city -Palestine Participants: school children aged 6 - 11 years studying in 1st to 6th class. Study period: March 2013 to June 2013. Sample size: 1063 school children which included 478 females and 585 males. Study variables: manifest hypermetropic refractive error by age, sex and class, uncorrected, best corrected visual acuity and scientific achievement in school. Statistical analysis: Chi square test, proportions. Results: manifest hypermetropia is the most prevalent refractive error in primary school children in Gaza city irrespective of age or gender or eye . The prevalence of manifest hypermetropia is $45.3 \%$ for right eye and $46.7 \%$ for left eye. No statistically significant difference in scientific achievement in Arabic language or mathematics between children with various types of refractive errors. Conclusions: These data support the assumption that vision screening of school children in developing countries could be useful in detecting correctable causes of decreased vision especially refractive errors and in minimizing long term visual disability.
\end{abstract}

Keywords: Prevalence, Manifest Hypermetropia, School Children, Age, Sex, Class, Uncorrected Visual Acuity, Best Corrected Visual Acuity

\section{Introduction}

The global initiative for the Elimination of Avoidable Blindness sets a major challenge to work relentlessly to avoid the preventable blindness. This initiative will also require both government and private sector's commitment to allocate more budgets to increase significantly the provision and uptake of eye care services. Refractive errors have been listed, along with cataract, trachoma, onchocerciasis and childhood blindness, among eye problems whose prevention and cure should provide enormous savings and facilitate societal developments. 1

The number of visually impaired persons in the world is about 259 millions. This estimate includes 98 millions persons with visual impairment due to uncorrected refractive error. ${ }^{2}$

Uncorrected refractive errors are an important cause of visual impairment in many countries. In a study conducted at New Delhi, refractive error was the cause in $81.7 \%$ of eyes with vision impairment. ${ }^{3}$ The refractive error was responsible for $1.1 \%$ legal blindness (which is defined as vision less than 6/60) and $0.5 \%$ economic blindness reported by Kalikivayi. ${ }^{4}$

Dandona et al estimated $12.3 \%$ total blindness was due to uncorrected refractive error, which is also responsible for a large number of blind years lived by a person than most other causes if left uncorrected. It was estimated that blindness due to refractive error resulted on an average of 30 years of blindness for each person as compared with 5 years of blindness due to untreated cataract for each person. $^{2}$

Refractive errors is an optical problem which prevent the formation of clear image on the retina .

Hypermetropic refractive error necessitate the use of accommodation in order to get a clear focus. Some times the degree of hypermetropia is beyond the accommodative capacity and so a defocused image well form on the retina .

Distance as well as near vision are both needed for students, so the problem of hypermetropic refractive error is important, because uncorrected hypermetropia may result in decreased vision and may eventually cause amblyopia .

Population based data concerning the prevalence of 
refractive errors in general or hypermetropia in particular in children are not readily available for Palestine. There have been reports of refractive errors for population of other countries, but very little has been reported for Palestine population .

The present study was carried out in the schools of Gaza city.

Students of the age group 6-11 years were chosen because refractive errors are most prevalent in this age group, and the possibility to treat refractive error and amblyopia is still possible in this age group.

This study presents the prevalence of manifest hypermetropia by age, sex, class, uncorrected, best corrected visual acuity and scientific achievement in school.

This information may be used for planning appropriate eye care program for high risk groups in order to reduce the burden of visual impairment in the population .

\section{Materials and Methods}

A population-based cross-sectional study, sought to estimate the prevalence of manifest hypermetropia in Gaza city. The present study included only the primary school children. The study area is Gaza city. Four primary schools were randomly selected in Gaza city.

The primary school children constitute about $15.4 \%$ of Palestinian population in Gaza city, according to the Palestinian central bureau of statistics 2007.
The study was conducted between March 2013 and June 2013.

Each child underwent autorefractometry, uncorrected distance visual acuity and best corrected visual acuity if her/his vision in not $6 / 6$. Also scientific achievement in Arabic language and mathematics was known for each child from school data.

Each child who has eye problem other than refractive error ( for example corneal opacity )was excluded from the study .

Each child with $+0.25 \mathrm{D}$ or more was considered to have manifest hypermetropia.

Significance was assigned at $\mathrm{P}<0.05$ level.

Categorical variables between groups were compared with the $X^{2}$ test or the Fisher exact test. The t-test was used for continuous variables. Trends with age were analyzed with $X^{2}$ analysis for trend. Data analysis was performed by SPSS and EPINFO.

\section{Results}

One thousand sixty three (1063) participants were included in our study, of them there were $478(45.0 \%)$ females and $585(55.0 \%)$ males. The class room ranged from first class to sixth class according to age from 6 years to 11 years, with mean age $(8.72 \pm 1.64)$. The mean age of females and males was $(9.07 \pm 1.65)$ and $(8.44 \pm 1.58)$ respectively (statistically significant student-t test $=6.396$, p-value $<0.001$ ) table 1.

Table (1) : the distribution of female and male students among primary school classes

\begin{tabular}{|c|c|c|c|c|c|c|}
\hline \multirow{2}{*}{$\frac{\text { Class room }}{1^{\text {st }}}$} & \multicolumn{2}{|c|}{$\begin{array}{c}\text { Female } \\
(n=478)\end{array}$} & \multicolumn{2}{|c|}{$\begin{array}{c}\text { Male } \\
(n=585)\end{array}$} & \multirow{2}{*}{$\begin{array}{c}\text { Total } \\
98\end{array}$} & \multirow{2}{*}{$\frac{(n=1063)}{(9.2 \%)}$} \\
\hline & 66 & $(67.3 \%)$ & 32 & $(32.7 \%)$ & & \\
\hline $2^{\text {nd }}$ & 22 & $(10.6 \%)$ & 185 & $(89.4 \%)$ & 207 & $(19.5 \%)$ \\
\hline $3^{\mathrm{rt}}$ & 72 & $(34.4 \%)$ & 137 & $(65.6 \%)$ & 209 & $(19.7 \%)$ \\
\hline $4^{\mathrm{rt}}$ & 69 & $(53.5 \%)$ & 60 & $(46.5 \%)$ & 129 & $(12.1 \%)$ \\
\hline $5^{\mathrm{rt}}$ & 150 & $(68.5 \%)$ & 69 & $(31.5 \%)$ & 219 & $(20.6 \%)$ \\
\hline $6^{\mathrm{rt}}$ & 99 & $(49.3 \%)$ & 102 & $(50.7 \%)$ & 201 & $(18.9 \%)$ \\
\hline \multirow[t]{2}{*}{ Total } & 478 & $(45.0 \%)$ & 585 & $(55.0 \%)$ & 1063 & $(100.0 \%)$ \\
\hline & & student- & \multicolumn{2}{|c|}{ p-value $<0.001$} & & \\
\hline
\end{tabular}

Of the whole sample the most prevalent refractive error was manifest hypermetropia reaching $45.3 \%$ for right eye and $46.7 \%$ for left eye.
The second most prevalent refractive error was astigmatism which reached $34.4 \%$ for right eye and $35.1 \%$ for left eye.

Table (2) : the prevalence of various types of refractive errors for right and left eye among primary school classes.

\begin{tabular}{|c|c|c|c|c|c|c|c|}
\hline \multirow[b]{2}{*}{ Class room } & \multirow[b]{2}{*}{$\mathbf{N}$} & \multicolumn{3}{|c|}{ Left auto refraction } & \multicolumn{3}{|c|}{ Right auto refraction } \\
\hline & & Myopia & Hyperopia & Astig. & Myopia & Hyperopia & Astig. \\
\hline $1^{\text {st }}$ & 98 & $16.3 \%$ & $53.1 \%$ & $37.8 \%$ & $13.3 \%$ & $62.2 \%$ & $30.6 \%$ \\
\hline $2^{\text {nd }}$ & 207 & $23.7 \%$ & $46.9 \%$ & $30.4 \%$ & $26.1 \%$ & $43.0 \%$ & $32.4 \%$ \\
\hline $3^{\mathrm{rt}}$ & 209 & $13.4 \%$ & $56.5 \%$ & $33.0 \%$ & $13.9 \%$ & $57.4 \%$ & $31.6 \%$ \\
\hline $4^{\mathrm{rt}}$ & 129 & $20.9 \%$ & $37.2 \%$ & $36.4 \%$ & $24.0 \%$ & $37.2 \%$ & $32.6 \%$ \\
\hline $5^{\mathrm{rt}}$ & 219 & $24.2 \%$ & $41.1 \%$ & $36.1 \%$ & $29.2 \%$ & $37.9 \%$ & $35.2 \%$ \\
\hline $6^{\mathrm{rt}}$ & 201 & $18.4 \%$ & $45.3 \%$ & $38.8 \%$ & $27.4 \%$ & $40.3 \%$ & $41.8 \%$ \\
\hline Total & 1063 & $19.7 \%$ & $46.7 \%$ & $35.1 \%$ & $23.1 \%$ & $45.3 \%$ & $34.4 \%$ \\
\hline \multicolumn{2}{|c|}{ Coefficient } & 0.439 & 0.423 & 0.726 & 0.660 & 0.554 & 0.708 \\
\hline \multicolumn{2}{|c|}{ Significant } & 0.384 & 0.404 & 0.102 & 0.154 & 0.255 & 0.115 \\
\hline
\end{tabular}


The third and least prevalent refractive error( but still a common one ) is myopia reaching $23.1 \%$ for right eye and $19.7 \%$ for left eye.

This sequence of prevalence keeps true for all classes from first to sixth.

The most prevalent type of astigmatism irrespective of eye (right or left) or severity (mild, moderate, severe and extreme ) was with the rule astigmatism.

The second most prevalent type was against the rule followed by oblique astigmatism.

Exception was in the right eye for extreme astigmatism in which all cases was of the oblique type ( table 3 ).

Table 3 : the prevalence of various types of astigmatism for right and left eye according to severity .

\begin{tabular}{|c|c|c|c|c|c|c|}
\hline \multirow[t]{2}{*}{ Cylinder } & \multicolumn{3}{|c|}{ Left auto refraction } & \multicolumn{3}{|c|}{ Right auto refraction } \\
\hline & with & against & oblique & with & against & oblique \\
\hline mild & $49.10 \%$ & $29.60 \%$ & $21.30 \%$ & $39.50 \%$ & $42.30 \%$ & $18.10 \%$ \\
\hline Moderate & $71.10 \%$ & $21.10 \%$ & $7.90 \%$ & $57.70 \%$ & $25.40 \%$ & $16.90 \%$ \\
\hline Severe & $77.80 \%$ & $11.10 \%$ & $11.10 \%$ & $100 \%$ & $0.00 \%$ & $0.00 \%$ \\
\hline Extreme & $100 \%$ & $0.00 \%$ & $0.00 \%$ & $0.00 \%$ & $0 \%$ & $100.00 \%$ \\
\hline Total & $19.10 \%$ & $9.60 \%$ & $6.40 \%$ & $15.50 \%$ & $12.90 \%$ & $6.30 \%$ \\
\hline $\mathbf{X} 2$ & \multicolumn{2}{|c|}{$473.3(0.000)$} & \multicolumn{4}{|c|}{$641.5(0.000)$} \\
\hline
\end{tabular}

There was no significant difference in the mean of academic achievement in Arabic language between myopes and hypermetropes. (t-test $=-1.81, \mathrm{p}$-value $>0.05$ ), there was no significant difference in the mean of academic achievement in mathematics between myopes and hypermetropes (t-test $=-0.221$, $\mathrm{p}$-value $>0.05$ ).

Tables 4 and 5 show the uncorrected and best corrected visual acuities for left and right eyes respectively and compare various types of refractive errors with each others.

Table 4 : left eye uncorrected and best corrected visual acuity for various types of refractive errors.

\begin{tabular}{|c|c|c|c|c|c|c|c|c|}
\hline & \multicolumn{4}{|c|}{ LT-ucva } & \multicolumn{4}{|c|}{ LT-bcva } \\
\hline & $6 / 6$ & $6 / 9-6 / 12$ & $6 / 18-6 / 36$ & $6 / 60$ or less & $6 / 6$ & $6 / 9-6 / 12$ & $6 / 18-6 / 36$ & $6 / 60$ or less \\
\hline Pure Hyperopia & $88.1 \%$ & $6.0 \%$ & $3.3 \%$ & $2.6 \%$ & $97.0 \%$ & $1.0 \%$ & $0.7 \%$ & $1.3 \%$ \\
\hline Astigmatism Hyperopia & $90.7 \%$ & $5.7 \%$ & $2.6 \%$ & $1.0 \%$ & $97.4 \%$ & $2.1 \%$ & $0.0 \%$ & $0.5 \%$ \\
\hline Pure Myopia & $89.7 \%$ & $5.9 \%$ & $2.9 \%$ & $1.5 \%$ & $97.1 \%$ & $1.5 \%$ & $0.7 \%$ & $0.7 \%$ \\
\hline Astigmatism Myopia & $95.9 \%$ & $4.1 \%$ & $0.0 \%$ & $0.0 \%$ & $100.0 \%$ & $0.0 \%$ & $0.0 \%$ & $0.0 \%$ \\
\hline Normal & $89.7 \%$ & $6.0 \%$ & $2.4 \%$ & $2.0 \%$ & $97.2 \%$ & $1.6 \%$ & $0.8 \%$ & $0.4 \%$ \\
\hline Normal with Astigmatism & $89.5 \%$ & $2.9 \%$ & $5.7 \%$ & $1.9 \%$ & $97.1 \%$ & $1.0 \%$ & $1.0 \%$ & $1.0 \%$ \\
\hline
\end{tabular}

LT-ucva : left uncorrected visual acuity, LT-bcva : left best corrected visual acuity.

Table 5 : right eye uncorrected and best corrected visual acuity for various types of refractive errors .

\begin{tabular}{|c|c|c|c|c|c|c|c|c|}
\hline & \multicolumn{4}{|c|}{ RT-ucva } & \multicolumn{4}{|c|}{ RT-bcva } \\
\hline & $6 / 6$ & $6 / 9-6 / 12$ & $6 / 18-6 / 36$ & $6 / 60$ or less & $6 / 6$ & $6 / 9-6 / 12$ & $6 / 18-6 / 36$ & $6 / 60$ or less \\
\hline Pure Hyperopia & $88.4 \%$ & $6.3 \%$ & $3.0 \%$ & $2.3 \%$ & $96.7 \%$ & $1.3 \%$ & $0.7 \%$ & $1.3 \%$ \\
\hline Astigmatism Hyperopia & $94.3 \%$ & $3.6 \%$ & $0.5 \%$ & $1.5 \%$ & $97.4 \%$ & $2.1 \%$ & $0.0 \%$ & $0.5 \%$ \\
\hline Pure Myopia & $89.7 \%$ & $5.1 \%$ & $5.1 \%$ & $0.0 \%$ & $97.8 \%$ & $0.7 \%$ & $1.5 \%$ & $0.0 \%$ \\
\hline Astigmatism Myopia & $95.9 \%$ & $2.7 \%$ & $1.4 \%$ & $0.0 \%$ & $98.6 \%$ & $1.4 \%$ & $0.0 \%$ & $0.0 \%$ \\
\hline Normal & $91.7 \%$ & $5.2 \%$ & $2.0 \%$ & $1.2 \%$ & $98.8 \%$ & $0.8 \%$ & $0.4 \%$ & $0.0 \%$ \\
\hline Normal with Astigmatism & $90.5 \%$ & $4.8 \%$ & $2.9 \%$ & $1.9 \%$ & $97.1 \%$ & $1.9 \%$ & $0.0 \%$ & $1.0 \%$ \\
\hline
\end{tabular}

RT-ucva: right uncorrected visual acuity, RT-bcva: right best corrected visual acuity .

From tables 4 and 5 the percent of visual acuity $6 / 60$ or less vision is highest for hypermetropia.

\section{Discussion}

In the present study, prevalence of manifest hypermetropia was found to be $45.3 \%$ for right eye and $46.7 \%$ for left eye. As it is known that most children at birth are hypermetropic and after the age of two years there may be an increase in hypermetropia and it may continue to increase until the age of 6 years, leveling off between the ages of 6 and 8 years and subsequently decreases5. According to these data our study found that the most prevalent refractive error in primary school children is hypermetropia and this is logic. In fact we could detect those with manifest hypermetropia but we know that if 
cycloplegia was used the percent of hypermetropic children would be more than what was found regarding manifest hypermetropia. At the same time as much of those who are hypermetropic have in fact mild hypermetropia and that children in this age group can easily overcome this mild hypermetropia by the act of accommodation so there is no problem with mild hypermetropia.

The percent of eyes that has best corrected visual acuity $6 / 60$ or less is highest among hypermetropic children ( $1.3 \%$ for either eye ).

Refractive errors did not differ significantly between males and females. However, in other studies ${ }^{6,7}$ refractive errors were found more commonly in girls than in boys, probably related to their rate of growth. Girls attain puberty earlier on an average and reach their final body weight 1-2 years earlier than the boys.

\section{Conclusion}

The data support the assumption that vision screening of school children in developing countries could be useful in detecting correctable causes of decreased vision especially refractive errors and in minimizing long term visual disability.

\section{Recommendations}

The present study shows that the child age group forms the high risk group for refractive errors and most of the children are unaware of refractive errors. Due emphasis must, therefore, be laid upon the screening for refractive errors in this age group. Moreover, attention should be paid to visual hygiene. While reading illumination should be good and adequately arranged. Posture should be easy and natural. Clarity and print should be carefully supervised. An undue ocular fatigue should be avoided. Students should have as many outdoor hours as possible. Students need to be educated about signs and symptoms of refractive errors. Pre-school and school screening for detection of refractive errors should be carried out on periodic basis.

\section{Acknowledgements}

we wish to acknowledge the help of optometrists and optometry department students who helped us in this study. we also thank research affairs of the Islamic UniversityGaza for their support.

\section{References}

[1] Murthy GVS. Vision Testing for Refractive Errors in Schools 'Screening' Programmes in Schools. Journal of Community Eye Health 2000;13: 3-5.

[2] Dandona L, Dandona R. What is the global burden of visual impairment? BMC Medicine 2006;4:6, Available at http:/www.biomedcentral.com/1741-7015/4/6

[3] Murthy GV, Gupta SK, Ellwein LB, Munoz SR, Pokharel GP, Sanga L, et al . Refractive error in an urban population in New Delhi. Invest Ophthalmol Vis Sci 2002;43: 623-31.

[4] Kalikivayi V, Naduvilath TJ, Bansal AK, Dandona L. Visual impairment in school children in Southern India. Indian J Ophthalmol 1997;45:129-34.

[5] Kanski JJ, Bowling B . Clinical Ophthalmology systematic approach . seventh edition. 2011;18:764

[6] Tay MT et al: Myopic and educational attainment in 421116 young Singaporean males, Ann Acad Med, Singapore, 1992, 21(6): 785-91.

[7] Venkatramana K, Naduvilam T: Visual impairment in school children in Southern India, Ind. Jou. of Ophthalmol, 1997, 129-34. 